\title{
Habitat Restoration Planning for Anatolian Wild Sheep (Ovis gmelini anatolica Valenciennes, 1856) in Konya-Bozdağ, Turkey
}

\author{
Yasin ÜNAL ${ }^{1}$, Ahmet KOCA ${ }^{2}$, Abdulkadir ERYILMAZ ${ }^{2}$ and Mevlüt ZENBILCI' ${ }^{2}$ \\ 1. Department of Wildlife Ecology and Management, Faculty of Forestry Engineering, Suleyman Demirel University, Isparta 32260, \\ Turkey
}

2. Department of Wildife Ecology and Management, Faculty of Forestry Engineering, Graduate School of Natural and Applied Sciences, Suleyman Demirel University, Isparta 32260, Turkey

\begin{abstract}
Anatolian wild sheep is still exists only in Konya-Bozdağ Wildlife Development Area in the world. Because of the ongoing illegal hunting, habitat destruction, etc. starting in 1966, only a herd consisting of 35 individuals survived. Thereupon, in the same year, 42,000 ha of fieldshad were declared as a protected areaby the Ministry of Agriculture and Forestry. Following this period, the number has increased to 2,000 in 2005. In the studied area, due to the increasingly exceeded carrying capacity of the land, wild sheep tended to lower the nutritional value of plants. Malnutrition, illnesses, stress, etc. led to death, and population size decreased to 600. Based on this information, there are two main ways to make deteriorated habitat structure suitable for accommodation, growth and proliferation of Anatolian wild sheep individuals. The firstone is about carrying individuals to other natural areas, and the latter is the restoration work in this area. Restoration work on the outside to add nutrients to the living environment (artificial feeding) and arranging habitat work are implemented. Depending on the type of habitat restoration work, restoration on the entire area, plot-plot restoration and radiating from the center to the environment restoration form can be made.
\end{abstract}

Key words: Anatolian wild sheep (Ovis gmelini anatolica Valenciennes, 1856), Konya Bozdă̆, habitat restoration.

\section{Introduction}

Turkey shows the characteristics of a small continent in terms of the biological variety it contains. There are approximately 13,000 plant species, 170 mammal species, 460 bird species, 130 reptile species, 470 fish species and 60,000-80,000 insect species reported in Turkey [1]. While Anatolia is not a continent by itself, it carries the ecosystem and habitat properties that can be found in an entire continent. The reasons for this situation include that three different bio-climates are seen, and it contains three bio-geographical regions as Euro-Siberian, Iran-Turanian and Mediterranean; it contains the topographic, geologic, geomorphologic and soil varieties, and the wetlands such as seas, lakes,

Corresponding author: Yasin ÜNAL, master, main research field: wildlife ecology and management. rivers, freshwater, saltwater and alkaline water resources. It has altitude variations changing in the range of 0-5,000 meters, deep canyons and varying ecosystems, which was not influenced by the ice ages as much as Europe, the existence of the Anatolian Diagonal that connects Northern Anatolia to Southern Anatolia, and the connected ecological and floristic variability, as well as its location in the intersection of three continents.

Turkey, which is among the European and Middle Eastern countries with the highest biological variability, holds the ninth place in Europe in terms of this factor. Each of the 7 geographical regions in Turkey shows different flora and fauna characteristics. There are a few different ecological regions in Turkey, each having their own endemic species and own natural ecosystems. The Euro-Siberian bio-geographical 

In Konya-Bozdağ, Turkey

region extends along Northern Anatolia and the parts of Thrace facing the Black Sea. It is the rainiest climate region and covered vastly with forests. The Mediterranean bio-geographical region covers all regions along the Mediterranean as well as western coasts of Thrace, and contains numerous types of ecosystems. The Iran-Turanian bio-geographical region is the largest of these and it extends from Central Anatolia to Mongolia. Continental climate and steppe plants are dominant in the region [1].

Anatolian wild sheep, which is among the mammals in Turkey and one of the 17 mammal species endemic to Turkey, is one of the 15 subspecies of the Asian mouflon which is one of the 5 wild sheep species in the Bovidae family of the Ungulata order. It still lives only in the Wildlife Development Area in Bozdağ, Konya. The place of the Anatolian wild sheep in the systematics is as shown in Table 1.

The Anatolian wild sheep, with its short hair, short ears and tail, long and thin legs, is usually likened to cervidae rather than sheep, which is why it is called by different names in the public language such as "gazelle", "ceran", "mouflon" and "mountain sheep". Will sheep, having advanced auditory and visual sensory traits, have wide visual angles like almost all herbivores. Anatolian wild sheep, which are highly quick and agile animals, can run quickly towards peaks as their forelegs are shorter than their hindlegs. While female Anatolian wild sheep may be $80-90 \mathrm{~cm}$ tall and weigh 35-50 kilos, their rams may be 105-140 $\mathrm{cm}$ tall and weigh 45-75 kilos. Females usually reach sexual maturity at the age of 1.5 and males reach sexual maturity usually at the age of 3.5 , while their average life span is $15-18$ years. Their hair colour may change not only seasonally, but also through aging. While males older than 2 years have darker hair, the whitened spots to the sides of their hips become more visible as they age. Again, seen only in rams, the black manes that grow on their necks and chests are longer in older rams. While the hair length is about 3.5-4 cm, the mane can grow up to $9-10$ centimeters. This is why older rams have much more expressive appearances. Their hides, which are in harmony with the land they live on, provide them with advantages in camouflage. One of their most visible aspects is their massive horns. While these begin to grow while rams are approximately 4 months old, they grow further as they age. The horns start to bend upwards and outwards when they reach 5-6 years of age, and reach their maximum size at the age of 12-13. The rings on the horn, just like tree rings, reflect the age of the ram. The rings that are formed annually are darker than the ones that may occasionally appear monthly. Another important aspect of the horns is that they create status differences among rams. While rams with smaller horns are placed lower in the hierarchy in the herd, the ones with larger horns are places higher [2].

Male and female herds of Anatolian wild sheep spend almost 10 months of the year in separation. While males usually form herds containing 10-15 individuals, females form herds containing 18-20. In the case of a threat, an old and experienced sheep that is in the leader position of the herd stomps its foot, produces a whistle-like sound to warn the herd, and leads an escape to a safer location. Ram herds consist only of males which have reached sexual maturity. The male sheep that have not reached sexual maturity yet stay with female herds. Wild sheep form more

Table 1 The place of the Anatolian wild sheep in the systematics [2].

\begin{tabular}{|l|l|l|}
\hline Class & Mammalia & Mammals \\
\hline Order & Artiodactyla & Even-toed ungulate \\
\hline Suborder & Ruminantia & Ruminants \\
\hline Family & Bovidae & Cloven-hoofed \\
\hline Genus & Ovis & Sheep \\
\hline Species & Ovis gmelini & Wild sheep \\
\hline Subspecies & Ovis gmelini anatolica & Anatolian wild sheep \\
\hline
\end{tabular}


crowded and mixed herds only in the mating seasons. In these seasons, the herd leadership is usually taken on by an old female sheep. Seasonal behaviours vary in Anatolian wild sheep according to different periods. In summer months, females and males spend around 8-10 hours of their days grazing in separate herds and locations. Groups of rams, which begin to appear in the territories of females in the months of November to December enter violent fights over females. The winter emerging after the mating season pose the toughest period of the year for wild sheep. Wild sheep, which experience difficulty finding food under the snow, dig the ground and try to reach tubers and underground remainders leftover from the summer. Female and male herds get separated again in this period. Pregnant females leave the herd in May-June to give birth and move to locations that are hard to reach. Following the 5-month pregnancy, they live alone for some time, and they go back to the herd after a short time following the birth [3].

In the year 1966, only 35 individuals had survived as a result of ongoing factors such as illegal hunting, habitat destruction, etc. As a result of this, 42,000 ha of area were declared as a protected area by the Ministry of Agriculture and Forestry. 3,429 ha of this area were surrounded by wire fences and a farming area was established. In the following periods, the population in the farming area adapted to the steppe habitat well and their number reached 2,000 in the year 2005. As the utilized capacity of the studied area increasingly exceeded the optimum level, wild sheep turned towards plants with lower nutritional values. However, the malnutrition led to deaths caused by diseases and stress, and the population size decreased to 600 [4]. Distribution of Ovis gmelini species in Turkey (Fig. 1)

In the light of this information, there are two main methods to make the damaged habitat structure in Bozdağ, Konya suitable for the harbouring, reproduction and increase in population of Anatolian wild sheep. Firstly, relocation work to move the excess populations of individuals to other natural areas has been ongoing since 2005 in various ministry and university cooperation projects, and some successful relocation implementations were made. However, it is seen that a habitat restoration (protecting and improving the natural structure of the existing living environment) work is needed to bring the conditions of the remaining individuals up to a standard that is suitable.

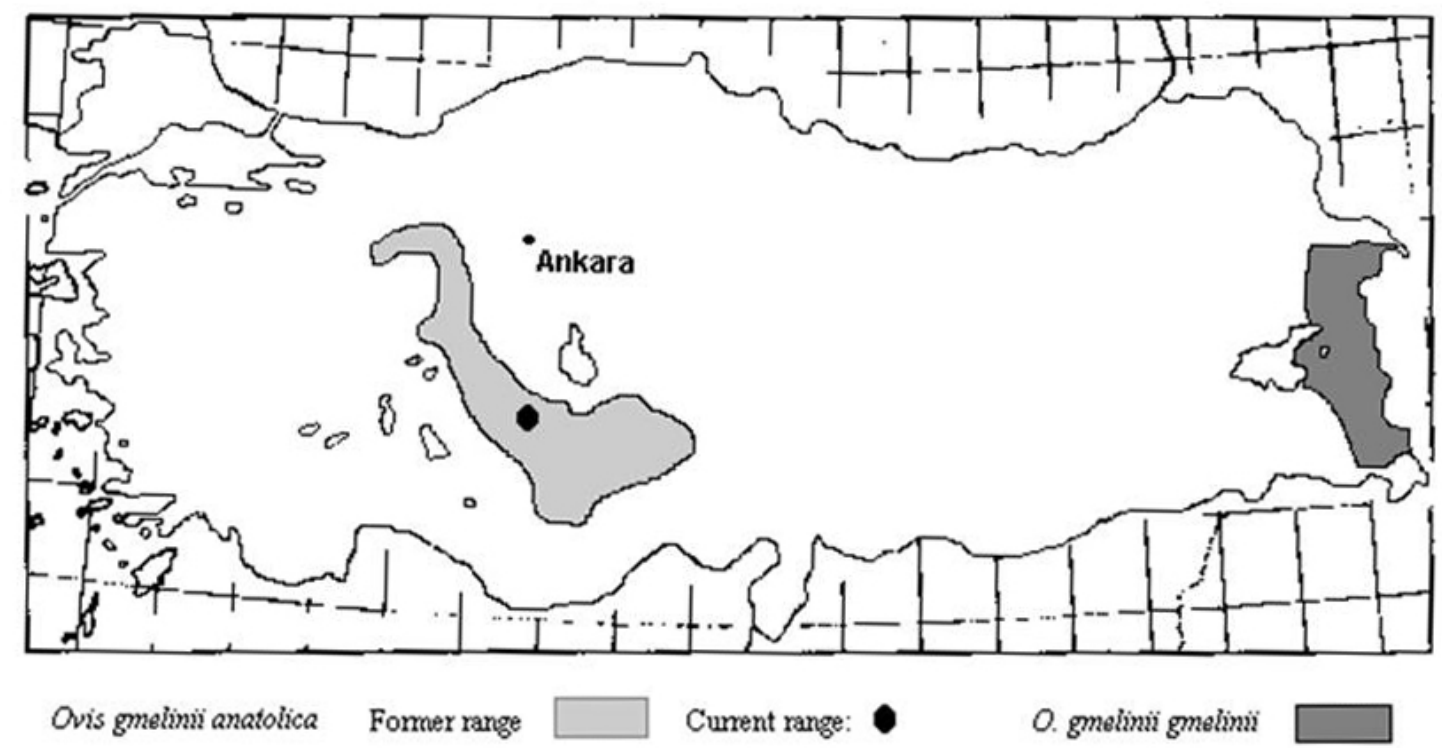

Fig. 1 Distribution of Ovis gmelini species in Turkey [5]. 
In this study (review), authors emphasise the restoration work to be conducted in order to provide higher quality distribution of the Anatolian wild sheep located in the Wildlife Development Area in Bozdağ, Konya.

\section{Description of the Problem and Solution Suggestions}

The Anatolian wild sheep subject to this study is located in the Wildlife Development Area in Bozdağ, Konya. Protected areas are described as territorial and/or naval areas that are allocated for a specific nature preservation purpose, designated to protect and sustain biological variety, natural and common cultural resources, and managed by legal or other effective methods. These areas provide the necessary space for the sustainability of ecological processes and the establishment of ecological restoration. There are 1,815 protected areas in Turkey. Among these, 1,773 are nationally, 16 are regionally, and 26 are globally protected. In addition to areas with geological, geomorphological,

landscape-historical, archaeological and cultural values, protected areas also contain areas that harbour numerous species of endemic, narrowly distributed plants and animals. 80 of the protected areas in our country were registered as Wildlife Development Areas in order to protect hunting and wild animals that became endangered [6].

The Bozdağ Wild Sheep Protection and Farming Area under the authority of the Directorate of Nature Conservation and National Parks, Konya District Office, was declared a Wild Sheep Protection Area as a result of the report by the Ministry of Agriculture officials in 1967 which stated that the population of Anatolian wild sheep dropped up to 50s. The land is located within the borders of Karatay, Selçuklu and Altınekin districts in the province of Konya, and an area of 60,000 ha was declared a Wildlife Development Area by the Cabinet decision numbered 2005/9453 and dated 07.09.2005 (Fig. 2). Between the year 1988 and 1992, a 3,500 area was surrounded by

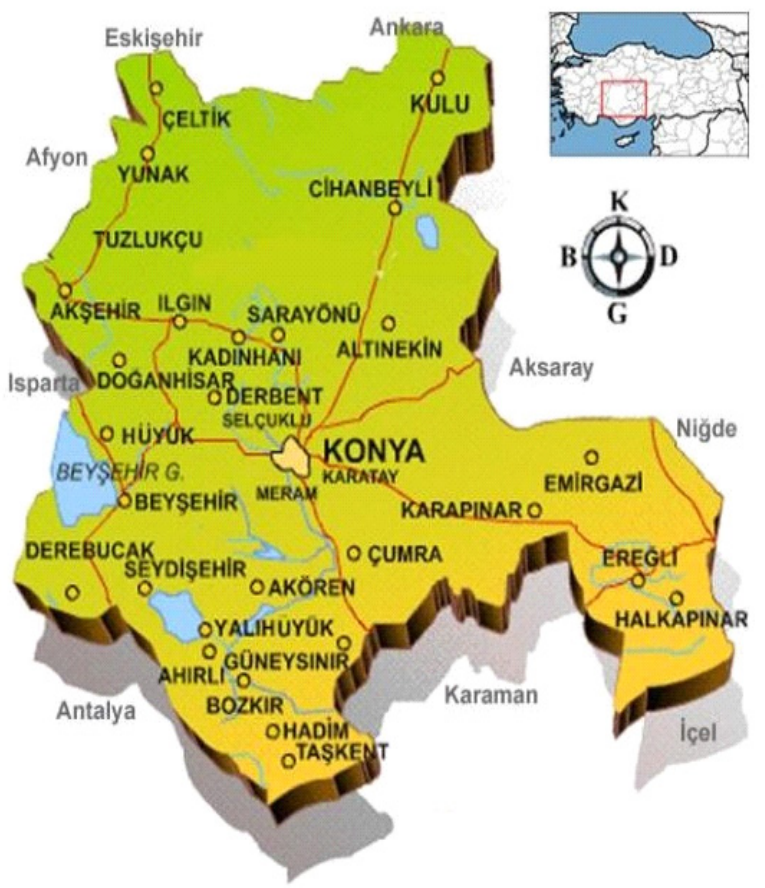

Fig. 2 Map of the Province of Konya and the Konya-Bozdağ Wildlife Development Area [8].

wire fences, and the wild sheep population reached 320 in 1986, 620 in 1998, 1,200 in 2001 and 2,000 in 2005. Currently, there are approximately 500 wild sheep in this engirdled area [7].

\subsection{Description of the Problem}

The most significant reasons for the rapid decrease in the population of the Anatolian wild sheep are as follows:

Decrease in resistance to diseases caused by lowered genetic variation (inbreeding) of the sheep in the protected area. The dramatic increase in the density of wild sheep in this limited area led to the rapid spread of the first encountered disease as an epidemic and caused effects among many individuals. It was indicated that paratuberculosis was influential in the decrease in population of the wild sheep.

Another factor is seen as the decrease in the amount and variety of plant resources in the area, which led to weakened immune systems of the animals.

Predator pressure is felt relatively weaker as the area is protected. 


\section{In Konya-Bozdağ, Turkey}

\subsection{Solution Suggestions}

1. Relocation to different areas;

2. Working to reach previous conditions using restoration in the area.

2.2.1 Implementations of Relocation to Different Areas

Relocation implementations are plans to resettle a species that disappeared or was made to disappear from its natural distribution area back into that area. In general, the purposes of relocation to different areas are: to protect and sustain genetic variety in the species, to further the survival of the species as it has exceeded its carrying capacity, to establish new reserve areas for endangered species, to provide the establishment of populations of the species in new habitats, and to revive new habitats that had been abandoned for any reason and became suitable in time, as well as damaged populations. This is important for increasing the genetic variety by lowering the rate of the founder effect in the protected area located in the wildlife development area in Konya-Bozdağ, and ensure the future of the herd against the danger of contagious disease faced by wild sheep in the area surrounded by wire fences. Therefore, relocation implementations were made for the Anatolian wild sheep in some areas: a total of 282 wild sheep were released into the nature in Ankara Nallihan (173), Karaman Karadağ (61), Malatya Hekimhan (20) and Bozdağlar Loras Mountain (28), and send to their previous habitats [9]. Socioeconomic and ecological conditions must be taken into account for relocation implementations. Regarding socioeconomic conditions: relocation projects should generally be long-term projects; beneficial and harmful effects on the residents should be analysed; the protection of the relocation project should be ensured by analysing all attitudes of residents; threats for humans should be communicated thoroughly and comprehensively, acceptance and support should be ensured by local governments; the relocation area should be immediately surrounded (by fences, etc.) in case of risks to the relocated population, and if the amount of relocation area is not sufficient, relocation should be interrupted and alternatives should be sought. Regarding ecological suitability: all planning and operations regarding the relocation of wildlife should be set on a rational basis, and there should be adequate knowledge about the ecology, biology and the population of the species. Whether the relocation area has the quality and capacity to contain a habitat again or not should be established by research and inventory work. Areas, where the species to be relocated had naturally spread, should be determined. The individuals farmed or raised in captivity should be subjected to adaptation programmes before being released into the nature. Foreign species should never be relocated in our country consciously and purposefully for any reason whatsoever.

\subsubsection{The Need for Bio-Restoration}

The decision to establish a specific living area that needs restoration will be made under these circumstances, if the target species turns to plants with lower nutritional value as an indicator of exceeding the habitat carrying capacity of the population, if there are dramatic levels of damage on plants and start of soil erosion as an indicator that the habitat can no longer satisfy the food and coverage requirements of the animals, if there is an emergence of signs of disease and stress, and in further stages, deaths in the animals that fall weak as a result of malnutrition, or if relocation is planned for wild animal species that had spread in the area previously, and there is a need to prepare the area for the said species [10]. The most important way and technique to protect and improve wild animal populations in habitat restoration implementations is improving food conditions, that is, the improvement of populations is facilitated by the improvement of food resources.

\subsection{Bringing the Area to Its Previous Condition through Restoration}

There are two methods to make the area usable by wild sheep on an optimum level through bio-restoration. 
2.3.1 Addition of Food to the Habitat from Outside (Artificial Feeding)

It is artificial feeding preferred relatively more in winter and in cases of malnutrition, using additional food. In the studied area, in snowy winter days and in some drought periods, caretakers place dried herbs and ready foods in locations visited by Anatolian wild sheep (Fig. 3). Wild sheep come from remote places to feeding stations to feed on these foods [11]. Anti-parasite drugs are included in their waterers and licking blocks containing salts and minerals are placed nearby $[12,13]$. However, this is a temporary measure and it is inadequate to contribute to feeding the population in a sustainable way. Instead of this, it would be more suitable to modify the habitat for more food to be produced in the living environment.

\subsubsection{Habitat Modification}

In this stage, information is collected via preliminary research regarding the previous conditions of the habitat; the damages it encountered up to the current state, habitat factors, and plant species preferred by the target species the most, and plantation implementations (habitat restoration) are made in the farming area for annual, biennial and perennial plants. Restoration work may be implemented in three different ways based on the types of habitats.

2.3.2.1 Restoration in the Entire Area

It is the restoration work performed in the entirety of a living environment. This method is preferred especially for open, flat, pasture areas. If there are wild animals spread in the studied area, the area is surrounded by wire-mesh fences while implementing the restoration.

\subsubsection{Parcel by Parcel Restoration}

In this bio-restoration method, the area is divided into parcels with a grid system. Parcels are indicated on a topographic map of $1 / 25,000$ before determining the priority areas in the light of the information gathered via preliminary research. The parcels are then numbered $(1,2,3 \ldots)$. The habitat type in each marked parcel is compared to the previous habitat type in the area. With the information taken from this analysis, the restoration work is performed, starting with the priority habitats that may satisfy the needs of target species. The previous area may be opened to the use of wild animals by moving on to the next parcel following the conclusion of restoration work.

\subsubsection{Radially Expanding Restoration}

In this method, a restoration work is conducted where there is a centre point of the habitat, expanding radially in stripes towards the edges of the map. While parcel by parcel restoration and radially expanding restoration are technically similar methods, they are the most suitable methods for large mammals such as the Anatolian wild sheep [10].

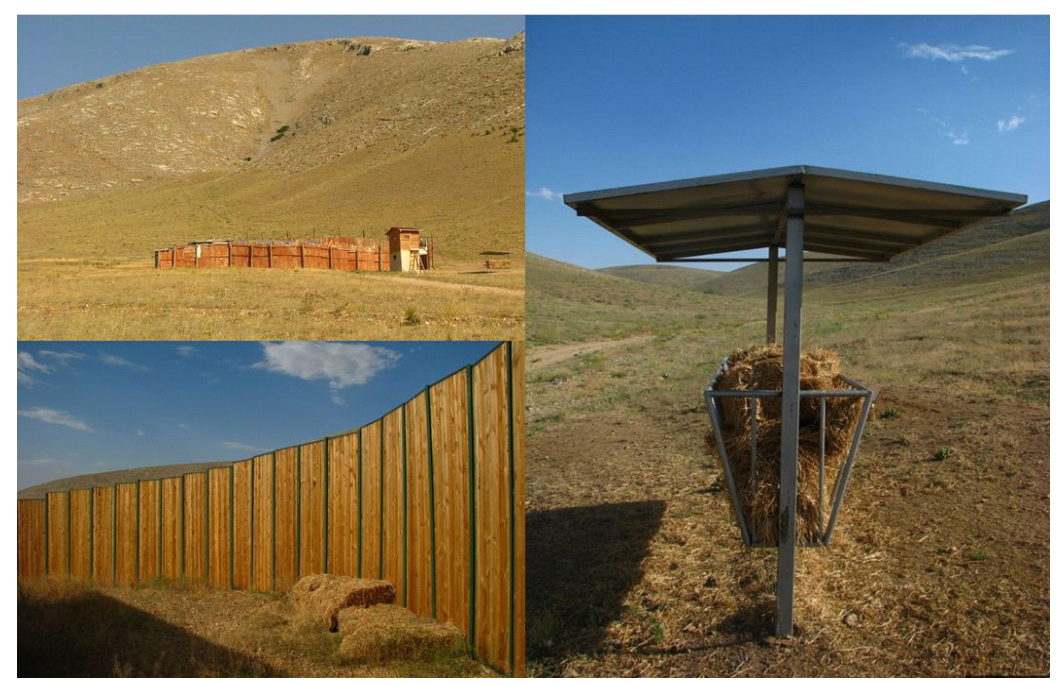

Fig. 3 Artificial feeding [14]. 


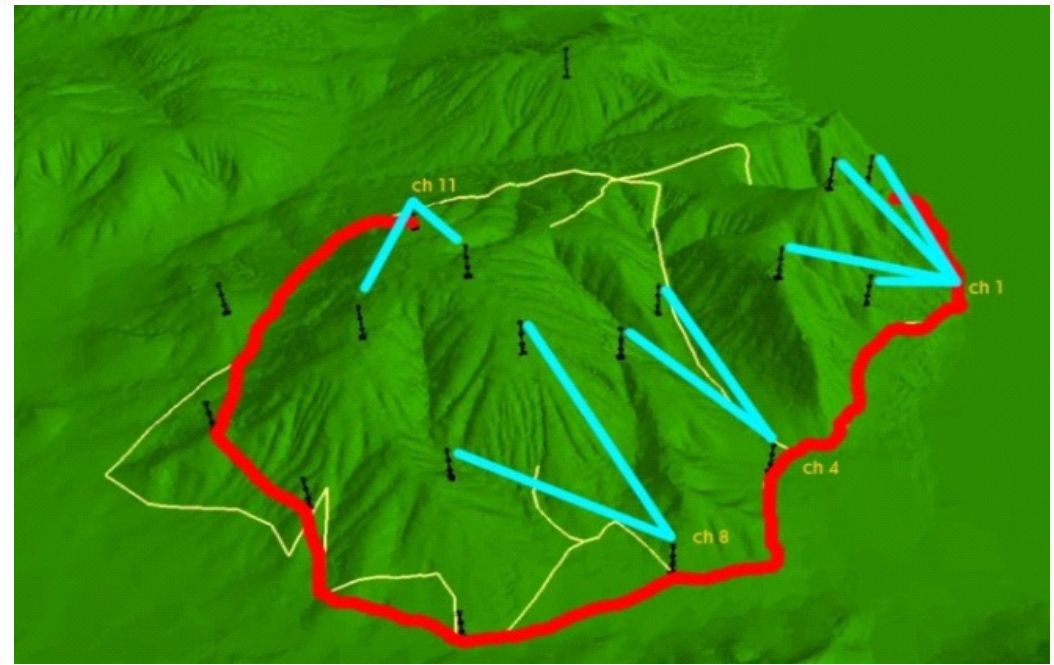

Fig. 4 The map of the area and its division based on specific criteria [14].

In the implementations towards these purposes:

- initially, the area will be divided into sections based on factors such as topographic structure, location and size;

- the divided parts will be surrounded by wire-mesh, animal movements will be restricted, and the area will be closed to usage, so that restoration work may start;

- then, land preparation, soil processing, species selection and restoration implementations will be performedafter analysing the physiographical, climatic, edaphic and vegetation information in hand (Fig. 4).

The restoration work to be performed will create a plan that is effective and useful for a relatively longer-term than artificial feeding. Placement and plantation of plants preferred by wild sheep will be made in the area surrounded for restoration. With this goal, members of the legume family that have relatively high rates of efficiency and protein (15-25\%) and mostly their mixtures with poaceae will be used. While planting these plants in mixtures increases the herbs' yield, it is reported that it also dramatically decreases the risk of intumescence in animals [15]. Possible food deficits that might arise in summers may be prevented by using tall, tasty and nutritious plants that can provide abundant leaves and grains such as corn and sorghum in summers in order to satisfy the need for green foods and grains. The sowing method in the restoration work is determined based on the structure of the area and the status of vegetation. In the areas where the vegetation is not completely destroyed, a sowing method with stripes suitable for the structure of the land should be preferred.

\section{Discussion and Conclusion}

As the Konya-Bozdağ wildlife development area is a closed protected area, live animal entrances and exits are very rare. While the populations in the area fluctuate in years, it is reported that they sometimes exceed the carrying capacity. In cases without an equilibrium, or in periods where there is an equilibrium but Anatolian wild sheep in the area exhausted the plants generally used for feeding in the area or exceeded the population equilibrium, it was found that they turn to plants that are not normally preferred, or plants with lower nutritional value in order to cover the food deficit. According to the studies in the literature and field research we conducted, it was determined that the Anatolian wild sheep seasonally consumed 52 genera in 19 families, and 76 taxa in these genera for feeding or other purposes. This number is estimated to be even higher. Some of these taxa are not seen in the area anymore, because of excessive consumption by the sheep. In the flora study conducted by İpekçi and Şanda between 
2003 and 2005, 257 genera in 57 families, and 482 taxa in these genera were found. The distribution of these taxa were determined as the following; Asteraceae 67 (14.0\%), Fabaceae 60 (12.6\%), Lamiaceae 57 (11.9\%), Brassicaceae 34 (7.1\%), Poaceae 30 (6.3\%), Rosaceae 24 (5.0\%), Caryophyllaceae 23 (4.8\%), Liliaceae 19 (4.0\%), Boraginaceae 17 (3.6\%) and Apiaceae 13 (2.7\%). Some of these detected species are used as food for small cattle. With comprehensive planning, inventory and research implementations, the area's vegetation may be strengthened by breeding the plants in these taxa with high nutritional value and adaptation ability.

\section{Reference}

[1] Genç, M. 2016. "The Biological Richness of Our Country, Turkey's Biodiversity and its Importance.” Online Web page. Accessed March 10, 2016. http://ulkemizin-biyolojik-zenginlikleri.nedir.org/.

[2] Mertyürek, B., and Baker, R. 2012. "Steppe Children Anatolian Wild Sheep, General Directorate of Nature Conservation and National Parks." Ministry of Forestry And Water Affairs Online Book. Accessed March 10, 2016. http://www.milliparklar.gov.tr/kitap/8/?sflang=tr\#p=2.

[3] Özüt, D. 2016. "Anatolian Wild Sheep Decreases." Online Web page. Accessed March 10, 2016. http://www.yabantv.com/haber/1540-anadolu-yaban-koy unu-azaliyor.

[4] Bilgin, C. 2016. "Turkish Mouflon (Ovis gmelini anatolica)." Online Web page. Accessed March 10, 2016. http://users.metu.edu.tr/cbilgin/gmelinii.htm.

[5] General Directorate of Nature Conservation and National Parks. 2016. Online Web page. Accessed March 10, 2016. http://www.milliparklar.gov.tr/korunanalanlar/korunanala n1.htm.

[6] Ministry of Forestry and Water Affairs 8. Regional
Directorate. 2016. Online Web page. Accessed March 10, 2016.

http://bolge8.ormansu.gov.tr/8bolge/anasayfa/yabanhayat igelistirmesahalari.aspx?sflang=t.

[7] Form of Uydulife. 2016. Online Web page. Accessed March 10, 2016. http://www.uydulife.net/konu/konya-ve-ilceleri-haritasi.2 $8906 /$.

[8] Duran, A. 2016. "Anatolian Wild Sheep Counted Individually.” Online Web page. Accessed March 10, 2016.

http://ekonomi.haber7.com/ekonomi/haber/824592-yaban -koyunlari-tek-tek-sayil.

[9] Oğurlu, I., Unal, Y., and Aksan, Ş. 2010. "Wild Life Biorestoration." In Proceedings of the Third National Congress of Black Sea Forestry, 1225-1231.

[10] Kaya, M. A. 1989. "Living at Bozdag (Konya) Anatolian Wild Sheep, Ovis gmelini anatolica (Mammalia: Artiodactyla)'s Biology.” Ph.D. thesis, Selçuk University.

[11] Kaya, M. A., and Aksoylar, Y. M. 1992. "Living at Bozdag (Konya) Anatolian Wild Sheep Ovis orientalis anatolica Valenciennes 1856 Behaviour." Natural Tar J. of Zoology 16 (241): 229-241.

[12] Çelik, M. 2004. "The İnvestigation of Some Behavioral Characteristics of Anatolian Wild Sheep (Ovis gmelini anatolica) by Using Telemetry and Observational Devices.” Ph.D. thesis, Selçuk University.

[13] Tüfekçi, M. B. 2007. Online Web page. Accessed March 10, 2016. http://wowturkey.com/forum/viewtopic.php?t=41290.

[14] General Directorate of Nature Conservation and National Parks. 2013. Online Web page. Accessed March, 2016. http://www.milliparklar.gov.tr/anasayfa/resimlihaber/13$11-12 /$ Yaban_Koyunlar $\% \mathrm{C} 4 \% \mathrm{~B} 1 \_\% \mathrm{C} 4 \% \mathrm{~B} 0 \% \mathrm{C} 3 \% \mathrm{~A} 7$ in _\%C4\%B0zleme_ve_G\%C3\%BCvenlik_Y\%C3\%B6neti m_Sistemi_Projesi_Hayata_Ge\%C3\%A7iriliyor.aspx?sfl ang $=$ tr.

[15] İpekçi, E., and Şanda, M. A. 2014. "The Flora of Bozdağ (Sizma-Konya-Turkey) and its Environs." ICBCS 2014: XII International Conference on Biological and Chemical Sciencess. 